\title{
Developing Legal-Entity Higher Education Institution (Perguruan Tinggi Negeri - Badan Hukum) as Centre of Excellence
}

\section{Kalihputro Fachriansyah ${ }^{1}$ and Endang Sulastri ${ }^{2}$}

\begin{abstract}
Affiliation Ministry of National Development Planning, Indonesia

Correspondence: kalih.fachriansyah@bappenas.go.id or endang.sulastri@bappenas.go.id
\end{abstract}

${ }^{1}$ Planner at Directorate for Higher Education, Science-Technology, and Culture,

${ }^{2}$ Acting Deputy Director for Higher Education, Directorate for Higher Education, Science-Technology, and Culture, Ministry of National Development Planning

\begin{abstract}
In the era of the knowledge and digital economy today, technology is no longer meant as a tool to increase productivity. Instead, it becomes a critical factor in creating added value. Higher education as an institution responsible for advancing science while producing innovative products of high economic value needs to be encouraged as a Centre of Excellence (CoE). Legal-Entity Higher Education Institution/Perguruan Tinggi Badan Hukum (PTN-BH) is considered more likely to become CoE in Indonesia. PTN-BH has the autonomy of academic and non-academic management. CoE criteria such as financial/funding, cooperation, governance, academic, and research-innovation are used in a gap analysis to determine the best policies to develop PTN-BH towards CoE. This study suggests that the center of science and technology excellence/Pusat Unggulan Iptek (PUI) can be a promising starting point towards CoE.
\end{abstract}

Keywords: higher education institution, center of excellence, world-class university.

Doi: https://doi.org/10.47266/bwp.v3i2.71 | page: 199-217

Submitted: July $01^{\text {st }} 2020$ | Accepted: August 08 ${ }^{\text {th }} 2020 \mid$ Published: September $07^{\text {th }} 2020$ 


\section{Introduction}

\subsection{Background}

In the past three decades, countries in Asia have progressively increased access to tertiary education (UNESCO, 2014). South Korea is the fastest-paced country, marked by an increase in the gross enrolment rate (GER) of tertiary education, which was initially less than 10 percent in 1980 to nearly 70 percent in 2011. The impact of the accumulation of a highly educated population in South Korea can be seen in the success of this country in creating technological innovations with high economic value. As the theory of endogenous economic growth, human capital characterized by education level has a significant influence on economic growth through technological processes (Fachriansyah, 2017).

Improvement in GER for higher education also occurs in Indonesia, increasing from 19.52 percent in 2010 to 30.28 percent in 2019. However, Indonesia's innovation capacity is still low. Referring to the 2018 Global Innovation Index (GII) (WIPO, 2019), Indonesia ranked 85 out of 126 countries with a GII score of 29.8 (on a scale of 0-100). With the achievements of the GII, Indonesia ranks only 13 th out of 30 lower-middle-income countries or rank 14th out of 15 Southeast Asian and Oceania countries. The weak point of Indonesia's innovation capability lies in not supporting regulations and laws, lack of research and development (R\&D) budget, limited access and use of information and communication technology, as well as a limited number of international patents.

Indonesia still does not have a solid foundation to sustain the knowledge economy. Workers with low education still dominate the profile of Indonesian workers. National Labour Statistics Data (Sakernas) in 2018 shows that as many as 58.8 percents of the workforce are junior high school graduates and below. Only 9 percent are graduates of tertiary education (Bappenas, 2018). A highly skilled workforce is needed to deal with changes in the work environment in the era that relies heavily on technology. In such a context, we need to consider higher education institutions responsible for delivering quality graduates, who become educated, knowledgeable, skilled, and master's in science and technology.

Higher education plays a central role in building capabilities for scientific development, knowledge production, technology adoption, and innovation creation. Two essential roles of higher education are (1) as an institution to generate quality and competitive human resources and (2) as a research center for the development of science and the creation of technological innovations. The second role is very closely related to the function of a center of excellence (CoE).

Improving the quality of higher education institutions (HEI) becomes a crucial issue. To accelerate economic growth, the Government needs to prepare the nation's innovation capabilities, in particular through the development of HEI as CoE. Hellstrom (2017) identified six components of $\mathrm{CoE}$ formation, namely: the priority or focus of excellence, the ability to create new knowledge, the existence of strategic objectives both academic goals or objectives of solving socio-economic problems, the maturity of the organization and governance, the diversity of funding sources and the flexibility of their use, and the availability of qualified researchers. These six components will ultimately improve institutional competitiveness and foster recognition from outside the institution to further establish cooperation.

Legal Entity Higher Education Institution or Perguruan Tinggi Negeri-Badan Hukum (PTN-BH) has financial and academic 
management autonomy. Since the enactment of Law number 12 the year 2012 concerning Higher Education, the Government Regulation number 58 the year 2013 concerning Form and Mechanism of PTN-BH Funding, the Minister of Education and Culture Regulation number 88 the year 2014 concerning Transformation of State-owned HEI into PTN-BH, the Government has sought to improve the quality of higher education through the legal entity management pattern. The recent Minister of Education and Culture Regulation number 4 the year 2020 even promote more State-owned HEI transformation to PTN-BH by relaxing several requirements. The Ministry of Research, Technology and Higher Education (MoRTHE) ${ }^{1}$ allocates PTN-BH Funding Assistance (BPPTN-BH) and various other fiscal interventions to improve the quality of resources, research and development productivity, institutional quality, and innovation capacity. PTN-BH are encouraged to be able to improve their academic reputation towards World Class University (WCU) and strengthen the innovation of universities in the industry.

\subsection{Research Question}

The Government of Indonesia has been investing an extensive state budget (APBN) to fund PTN-BH in improving human capital and economic growth. It should be tested whether such a policy is justified and implemented effectively. Next, in terms of preparing national innovation capability, is PTN-BH could be Indonesia's best opportunity in developing $\mathrm{CoE}$ ? The answer is important for policy makers in deciding budget allocation among other alternative such as public research institutions.

\footnotetext{
1 Starting 2019 higher education becomes the responsibility of the Ministry of Education and Culture, while research and innovation managed under the Ministry
}

Accordingly, this study carried out to assess the impact of the PTN-BH policy, to measure the extent to which PTN-BH can be developed into a center of excellence through a five components $\mathrm{CoE}$ analysis approach, namely financial management, governance, academic, cooperation, as well as research and innovation in each PTN-BH, and to identify the problems and challenges faced in each $\mathrm{CoE}$ component. This paper is intended to answer whether PTN$\mathrm{BH}$ can be developed into $\mathrm{CoE}$.

\subsection{Research Methodology and Structure}

The study was undertaken in the eleven state universities which currently have legal entities, namely: Bandung Institute of Technology (ITB), Gadjah Mada University (UGM), Bogor Agricultural University (IPB), University of Indonesia (UI), Indonesia University of Education (UPI), University of North Sumatra (USU), Airlangga University (Unair), Padjadjaran University (Unpad), Diponegoro University (Undip), Hasanuddin University (Unhas), and the Ten November Institute of Technology (ITS).

A gap analysis method widely used in performance assurance system. It is used to measure the degree of performance gap compared to the desired quality of services. One example of gap analysis method in higher education sector was undertaken by Hrnciar and Madzik (2013). The authors analyzed performance gap in delivering higher education in Central Europe universities.

By the same token, our study utilized gap analysis in comparing the level of the current performance achieved compared to the expected ideal conditions in the five components of the CoE: funding and financial management, cooperation, governance, academic, and

of Research and Technology/National Board of Research and Innovation 


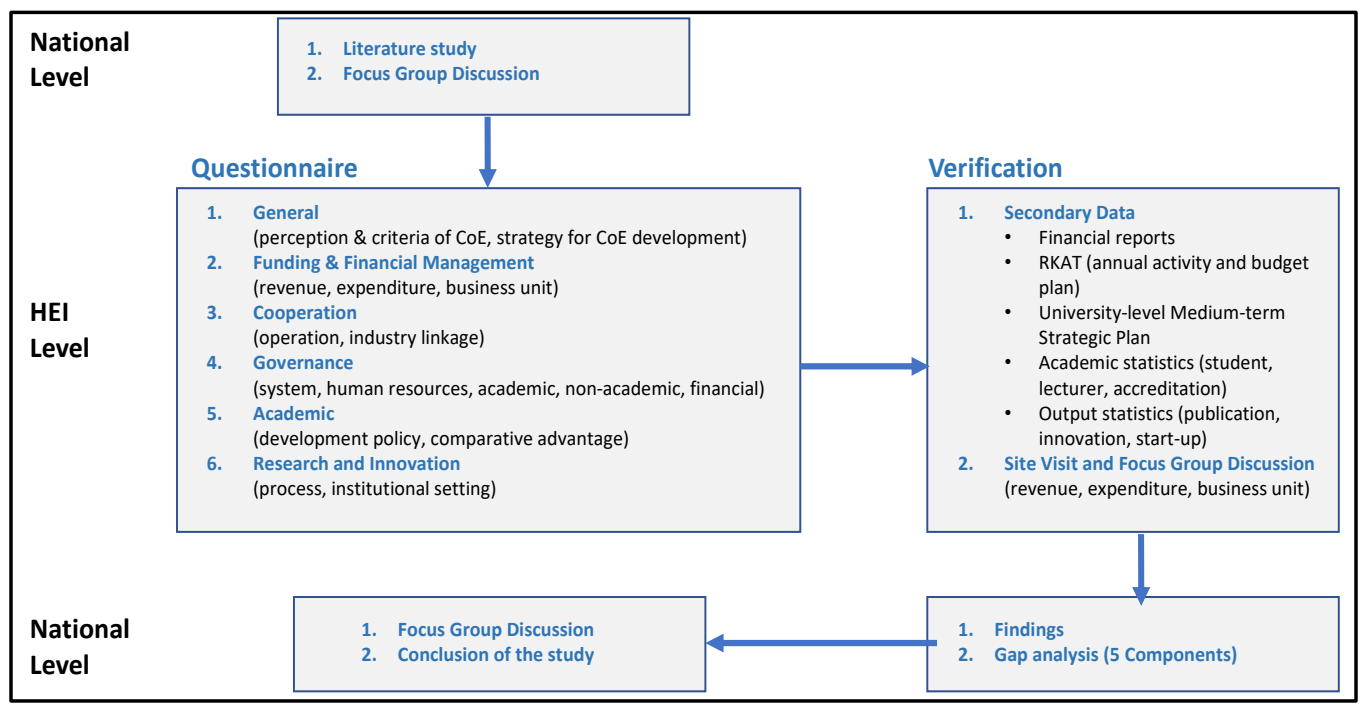

Figure 1. Research design

research-innovation. The ideal conditions of a $\mathrm{CoE}$ in each components are developed based on the optimum possibility achieved as PTN-BH. For instance, an ideal condition for funding and financial management component is PTN-BH can generate income from non-APBN rather than depending on APBN funds. Each PTN-BH answered an evaluation questionnaire instrument, supported by data, and clarified through focus group discussions at all eleven PTN-BH. In addition to data collection at PTN$\mathrm{BH}$, a series of thematic workshops at the national level also arranged to obtain a national point of view. Finally, the evaluation instruments and workshops' results are combined with information from the literature to be further analyzed and processed into policy recommendations.

The study is organized into five sections. Following this section, the national policy of PTNBH is discussed to understand the context. In the third section, field findings in the implementation of PTN-BH were explained. Accordingly, in Section IV, the findings were analyzed systematically in the framework of the five components of $\mathrm{CoE}$. The last section will conclude the study and provide policy recommendations for future improvement.

\section{National Policy Framework of PTN- BH}

The policy of establishing PTN-BH in Indonesia begins with the history of establishing HEI as a State-owned Legal Entity (PTBHMN) and HEI as an Educational Legal Entity (PTN-BHP). The policy regulated through Government Regulation number 61 the year 1999 concerning the Establishment of State-owned HEI as an entity law. This policy was initially set to accommodate particular needs in the privatization of educational institutions with non-profit characteristics despite being a business entity. In its journey, this policy caused opposition in the community due to fears of the increasingly high cost of higher education at State-owned HEIs. In this case, PTN-BHP is considered free to determine tuition fees to obtain appropriate profit to cover operational costs. In 2012 the Government issued Law number 12 the year 2012 concerning Higher Education. The Law marked the end of the of PTN-BHP policy, replaced by PTN-BH. 
The establishment of PTN-BH was driven by the need to create a State-owned HEI which independently manages its policies, academics, and finances. The transformation was carried out in stages to state universities that met the criteria set by the Minister of Education Regulation number 88 the year 2004 concerning Transformation State-owned HEI to PTN-BH. The first group of HEIs that transformed into PTN-BH were UI, ITB, IPB, and UGM in 2013, which enacted by Government Regulations. In 2014 (until today), the number of PTN-BH increased to eleven institutions with the entry of Undip, UPI, USU, Unpad, Airlangga University, ITS, and Hasanuddin University.

Classification of state-owned HEI management system is intended to differentiate the level of authority and performance targets set. In the Law No. 12/2012 (Article 65) and Government Regulation number 4 the year 2014 concerning the Implementation and Management of Higher Education (Article 27), the state-owned HEI management system is divided into three: state-owned HEI that applies the state financial management in general, commonly identified by the working unit (Satuan Kerja), state-owned HEI that applies the system of financial management of public service bodies (PTN-BLU), and state-owned HEI that has autonomous management (PTN-BH). These three systems characterize the autonomy level in management, where the PTN-BH has the most autonomous characteristics in academic and non-academic aspects.

The funding system is one crucial component that differentiates PTN-BH and PTN-BLU. In PTN-BH, planning and budgeting is not only based on the university strategic plan but also determined by the Board of Trustees (Majelis Wali Amanah) as the highest body in the university. The Board of Trustees represents the interests of the Government, the community, and the interests of the relevant tertiary institution. Planning and budgeting at PTN-BH are carried out by a particular section/unit at PTN-BH, namely the Directorate of Planning and Budgeting.

Implementation of the Government policy on PTN-BH is mainly translated through funding assistance called Bantuan Pendanaan PTN-BH (BPPTN-BH). As regulated by Government Regulation number 26 the year 2015 concerning Funding Form and Mechanism in PTN-BH, the amount of BPPTN-BH is given based on (a) standard calculation of the operational costs of PTN-BH; (b) revenue of PTN-BH; and (c) higher education efficiency and quality. The use of BPPTN-BH is limited only to fund: (a) operational costs, (b) lecturer, (c) non-academic staff costs, (d) investment, and (e) development.

Table 1. Main characteristics differences between PTN-BLU and PTN-BH

\begin{tabular}{clll}
\hline No. & \multicolumn{1}{c}{ Component } & \multicolumn{1}{c}{ PTN-BLU } & \multicolumn{1}{c}{ PTN-BH } \\
\hline 1 & status & the working unit of a ministry & legal entity \\
\hline 2 & $\begin{array}{l}\text { management } \\
\text { authority }\end{array}$ & $\begin{array}{l}\text { has authority in managing } \\
\text { funds received from the } \\
\text { community }\end{array}$ & $\begin{array}{l}\text { broad authority in academic } \\
\text { and non-academic }\end{array}$ \\
\hline 3 & budgeting & $\begin{array}{l}\text { based on HEI strategic plan, } \\
\text { proposed to the parent } \\
\text { ministry }\end{array}$ & $\begin{array}{l}\text { based on HEI strategic plan, } \\
\text { stipulated by Board of } \\
\text { Trustees }\end{array}$ \\
\hline 4 & revenue & $\begin{array}{l}\text { all revenue received from the } \\
\text { community should be }\end{array}$ & self-manage \\
& &
\end{tabular}




\begin{tabular}{|c|c|c|c|}
\hline & & $\begin{array}{l}\text { deposited to the Government } \\
\text { Treasury }\end{array}$ & \\
\hline 5 & tariff & $\begin{array}{l}\text { proposed by PTN-BLU to the } \\
\text { Ministry of Finance }\end{array}$ & $\begin{array}{l}\text { the chancellor has authority to } \\
\text { set tariff }\end{array}$ \\
\hline 6 & assets management & $\begin{array}{l}\text { Through the approval of } \\
\text { Minister of Finance }\end{array}$ & $\begin{array}{l}\text { has authority except for land } \\
\text { which is owned by the } \\
\text { Government }\end{array}$ \\
\hline 7 & $\begin{array}{l}\text { financial inspection } \\
\text { and supervision }\end{array}$ & $\begin{array}{l}\text { audited by National } \\
\text { Government Internal Auditor } \\
(\mathrm{BPKP})\end{array}$ & $\begin{array}{l}\text { external auditor (BPK) or } \\
\text { public accountant }\end{array}$ \\
\hline
\end{tabular}

Source: Law No. 12/2012

PTN-BH and the Government agreed on the use of BPPTN-BH to achieve particular performance targets. In general, seven targets become the performance contracts in the eleven PTN-BH, namely improved performance and accountability of state finances, the realization of good governance and service quality, improved quality of learning and student's affairs, increasing relevance, quality and quantity of resources, increasing relevance and productivity of research and development, increasing institutional quality, and strengthening innovation capacity. PTN-BH performance indicators can change every year according to the agreement and the government budget availability.

In addition to BPPTN-BH, which is transferred directly to PTN-BH, there are a variety of additional thematic interventions. These funding assistances are managed separately in echelon I units (directorategeneral) in the Ministry of Research and Technology. Some examples of interventions aimed at increasing the capacity of PTN-BH towards $\mathrm{CoE}$ include fostering and establishing leading science and technology centers, fostering candidates and technology-based start-ups, technology business incubation, assistance for higher education industry innovation, and incentives to increase university's global rank.

\section{PTN-BH in Practices}

\subsection{Performance Improvement}

PTN-BH outlined their activities into an Annual Work Plan and Budget/Rencana Kerja dan Anggaran (RKA) along with targeted performance indicators. PTN-BH performance is measured based on the achievement of targets in the performance contract and reported to the MoRTHE every year. PTN-BH's key performance report is also published, together with the externally audited financial statements. Both of these reflect the accountability of governance and budget execution in PTN-BH.

Several PTN-BH were able to exceed the performance targets that have been set in the RKA document. For example, ITB outperformed in indicators of the number of graduates employed within three months after graduation, the number of international publications, the number of industrial prototypes, and the number of citations of scientific work. UI has well-performed in indicators of the number of excellent accredited study programs (A) and the number of students winning gold medals at national and international levels. UGM related to the indicator of the percentage of graduates who immediately work and the percentage of graduates who have the competency and professional certificates. 
Table 2. PTN-BH key performance achievements in 2018

\begin{tabular}{|c|c|c|c|c|c|c|c|c|c|c|c|}
\hline $\begin{array}{c}\text { Main } \\
\text { Performance } \\
\text { Indicator }\end{array}$ & $\stackrel{\oplus}{E}$ & $\sum_{0}$ & $\stackrel{\varphi}{\varrho}$ & 5 & 5 & $\stackrel{\vartheta}{\mathscr{V}}$ & $\underset{Z}{Z}$ & $\begin{array}{l}\frac{9}{2} \\
\frac{1}{2} \\
5\end{array}$ & 言 & $\sum_{3}^{\infty}$ & $\stackrel{\mathscr{E}}{\underline{\theta}}$ \\
\hline $\begin{array}{l}\text { No of graduates } \\
\text { become } \\
\text { entrepreneurship }\end{array}$ & $\begin{array}{c}236 \\
\mathbf{\Delta}\end{array}$ & $\begin{array}{c}821 \\
\sim\end{array}$ & $\begin{array}{c}444 \\
\Delta\end{array}$ & $\begin{array}{l}280 \\
\Delta\end{array}$ & $\begin{array}{c}1.256 \\
\Delta\end{array}$ & $\begin{array}{c}648 \\
\Delta\end{array}$ & $\begin{array}{c}483 \\
\Delta\end{array}$ & $\begin{array}{c}397 \\
\Delta\end{array}$ & $\begin{array}{c}3.871 \\
\Delta\end{array}$ & $\begin{array}{c}364 \\
\Delta\end{array}$ & $\begin{array}{c}354 \\
\Delta\end{array}$ \\
\hline $\begin{array}{l}\text { \% of graduates } \\
\text { who immediately } \\
\text { employed }\end{array}$ & $\begin{array}{c}67 \% \\
\boldsymbol{\Delta}\end{array}$ & $\begin{array}{c}67 \% \\
\sim\end{array}$ & $\begin{array}{c}68 \% \\
\Delta\end{array}$ & $\begin{array}{c}98 \% \\
\Delta\end{array}$ & $\begin{array}{c}80 \% \\
\mathbf{\Delta}\end{array}$ & $\begin{array}{c}44 \% \\
\Delta\end{array}$ & $\begin{array}{c}64 \% \\
\Delta\end{array}$ & $\begin{array}{c}52 \% \\
\nabla\end{array}$ & $\begin{array}{c}55 \% \\
\ldots\end{array}$ & $\begin{array}{c}67 \% \\
\ldots\end{array}$ & $\begin{array}{c}62 \% \\
\nabla\end{array}$ \\
\hline $\begin{array}{l}\text { No of study } \\
\text { program that } \\
\text { internationally } \\
\text { accredited }\end{array}$ & 36 & 44 & 25 & 33 & 8 & 2 & 6 & 3 & 8 & 14 & 20 \\
\hline $\begin{array}{l}\text { \% of lecturer } \\
\text { holds a doctoral } \\
\text { degree }\end{array}$ & $\begin{array}{c}73 \% \\
\Delta\end{array}$ & $\begin{array}{c}55 \% \\
\Delta\end{array}$ & $\begin{array}{c}71 \% \\
\Delta\end{array}$ & $\begin{array}{c}59 \% \\
\boldsymbol{\Delta}\end{array}$ & $\begin{array}{c}45 \% \\
\boldsymbol{\Delta}\end{array}$ & $\begin{array}{c}37 \% \\
\Delta\end{array}$ & $\begin{array}{c}38 \% \\
\Delta\end{array}$ & $\begin{array}{c}43 \% \\
\ldots\end{array}$ & $\begin{array}{c}39 \% \\
\ldots\end{array}$ & $\begin{array}{c}63 \% \\
\ldots\end{array}$ & $\begin{array}{c}45 \% \\
\ldots\end{array}$ \\
\hline $\begin{array}{l}\text { No of } \\
\text { international } \\
\text { publication }\end{array}$ & $\begin{array}{c}1.870 \\
\Delta\end{array}$ & $\begin{array}{c}2.573 \\
\boldsymbol{\Delta}\end{array}$ & $\begin{array}{c}844 \\
\Delta\end{array}$ & $\begin{array}{c}2.946 \\
\mathbf{\Delta}\end{array}$ & $\begin{array}{c}614 \\
\sim\end{array}$ & $\begin{array}{c}1.701 \\
\Delta\end{array}$ & $\begin{array}{c}947 \\
\Delta\end{array}$ & $\begin{array}{c}847 \\
\ldots\end{array}$ & $\begin{array}{c}1.290 \\
\ldots\end{array}$ & $\begin{array}{c}1.140 \\
\ldots\end{array}$ & $\begin{array}{c}1.057 \\
\Delta\end{array}$ \\
\hline $\begin{array}{l}\text { No of Intellectual } \\
\text { Property } \\
\text { registered }\end{array}$ & $\begin{array}{l}77 \\
\Delta\end{array}$ & $\begin{array}{c}225 \\
\sim\end{array}$ & $\begin{array}{l}55 \\
--\end{array}$ & $\begin{array}{c}1.006 \\
\sim\end{array}$ & $\begin{array}{c}203 \\
\sim\end{array}$ & $\begin{array}{c}168 \\
\Delta\end{array}$ & $\begin{array}{c}78 \\
\mathbf{A}\end{array}$ & $\begin{array}{c}1.015 \\
\mathbf{\Delta}\end{array}$ & $\begin{array}{c}203 \\
\Delta\end{array}$ & $\begin{array}{l}- \\
\cdots\end{array}$ & $\begin{array}{l}29 \\
--\end{array}$ \\
\hline $\begin{array}{l}\text { No of R\&D } \\
\text { prototype }\end{array}$ & $\begin{array}{l}54 \\
\Delta\end{array}$ & $\begin{array}{l}55 \\
\Delta\end{array}$ & $\begin{array}{l}74 \\
\Delta\end{array}$ & $\begin{array}{l}1 \\
\nabla\end{array}$ & $\begin{array}{l}6 \\
\sim\end{array}$ & $\begin{array}{l}30 \\
\Delta\end{array}$ & $\begin{array}{l}17 \\
\Delta\end{array}$ & 44 & $\begin{array}{l}35 \\
--\end{array}$ & $\begin{array}{l}29 \\
\mathbf{\Delta}\end{array}$ & $\begin{array}{l}30 \\
\Delta\end{array}$ \\
\hline $\begin{array}{l}\text { No of } \mathrm{R} \& \mathrm{D} \text { in the } \\
\text { industry }\end{array}$ & $\begin{array}{l}65 \\
\Delta \\
\end{array}$ & $\begin{array}{l}15 \\
--\end{array}$ & $\begin{array}{l}32 \\
--\end{array}$ & - & $\begin{array}{l}3 \\
\Delta\end{array}$ & $\begin{array}{l}2 \\
\sim\end{array}$ & $\begin{array}{l}12 \\
\Delta\end{array}$ & 22 & $\begin{array}{l}10 \\
\Delta\end{array}$ & $\begin{array}{l}8 \\
--\end{array}$ & $\begin{array}{l}27 \\
\Delta\end{array}$ \\
\hline $\begin{array}{l}\text { No of innovation } \\
\text { product }\end{array}$ & $\begin{array}{l}8 \\
--\end{array}$ & 4 & $\begin{array}{l}6 \\
\sim\end{array}$ & $\begin{array}{l}2 \\
--\end{array}$ & - & $\begin{array}{l}16 \\
\Delta\end{array}$ & $\begin{array}{l}3 \\
\nabla\end{array}$ & $\begin{array}{l}3 \\
7\end{array}$ & $\begin{array}{l}2 \\
--\end{array}$ & 4 & $\begin{array}{l}10 \\
\nabla\end{array}$ \\
\hline No of start-up & 20 & 10 & 12 & 3 & - & 4 & 30 & 7 & 4 & 6 & 5 \\
\hline
\end{tabular}

Notes: The signs below show trend in the last three years $\boldsymbol{\Delta}$ (increased), $\boldsymbol{\nabla}$ (decreased), (fluctuated), -- (stagnant), ...(not enough data for analysis)

Source: Calculated from Bureau of Planning and International Cooperation presentation, MoRTHE, 2019

\subsection{Funding and Financial Management}

PTN-BH has the authorization to manage funds independently. The budgeting model in PTN-BH evolved from what the expenditure ceiling-based (PTN-BLU and PTN-Satuan
Kerja) to performance-based budgeting. In general, there are two primary funding sources in PTN-BH. First, the portion of revenue from the APBN is in the form of BPPTN-BH and other forms. Second, sources other than the APBN, such as funds from the community, tuition fees, endowment fund management, 
PTN-BH businesses, Tridharma ${ }^{1}$ cooperation, PTN-BH wealth management, local government (APBD), and loans. Out of those two sources of funding, the most substantial proportion (67 percent) comes from non-APBN. As much of 37 percent of that non-APBN income is the community funding (tuition fees).

The world-class university has similar features: a high concentration of talent, abundant resources, and favorable governance (Salmi, 2009). Based on RKAT of eleven PTN$\mathrm{BH}$ in 2019, the average amount of funding allocation per HEI was 1.59 trillion rupiahs. Funding at PTN-BH is too low to compete for the top rank in the world. The average government funding at benchmark universities in the world, such as the University of Malaya, Nanyang Technological University, and Wageningen University, reaches 4.22 trillion rupiahs, almost three times the average budget of PTN-BH in Indonesia. MoRTHE revealed that the Government should spend 3.7 trillion rupiahs more per PTN-BH to catch benchmark HEIs. On the other hand, the Government allocation for BPPTN-BH during the 2018-2020 period tended to be stagnant, around 5.06 trillion rupiahs annually for eleven PTN-BHs.

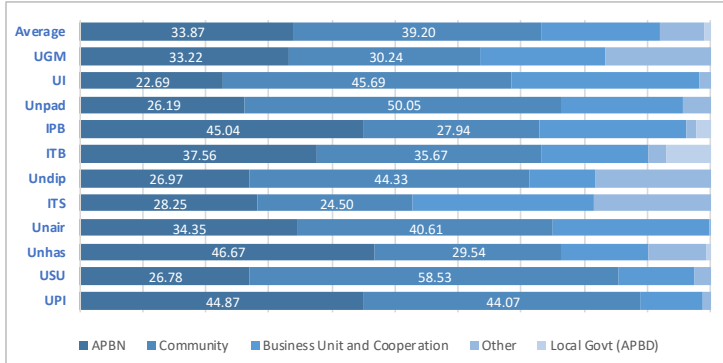

Figure 2. Proportion of PTN-BH revenue year 2019

Note: UPI used data for the year 2018

1 Tridharma of Higher Education is the ultimate mission of HEI in Indonesia, namely education, research, and community service
Most of the utilization of the allocation from the state budget is to finance operational needs. BPPTN-BH is used to fund the salaries and allowances of lecturers and teaching staff, investment, and operational costs to implement Tridharma of Higher Education. Meanwhile, funding sourced from non-APBN was utilized mainly for operational costs of conducting education and research components. For example, Unhas' funding sourced from the state budget is primarily used to finance operational needs, amounting to 558 billion rupiahs out of 1195 billion rupiah budget in 2019.

With funding from the state budget, the average funding allocation for research reaches 180 billion rupiahs per year. Most of the PTN$\mathrm{BH}$ research activities are funded by non-APBN. During 2017-2019, as many as 6 PTN-BH had allocated substantial funding for research through non-APBN funding sources, namely IPB, Unpad, Undip, ITS, Unair, and USU. In contrast, the allocation of research funding at other PTN-BH such as UPI is still relatively small and depends on the Government.

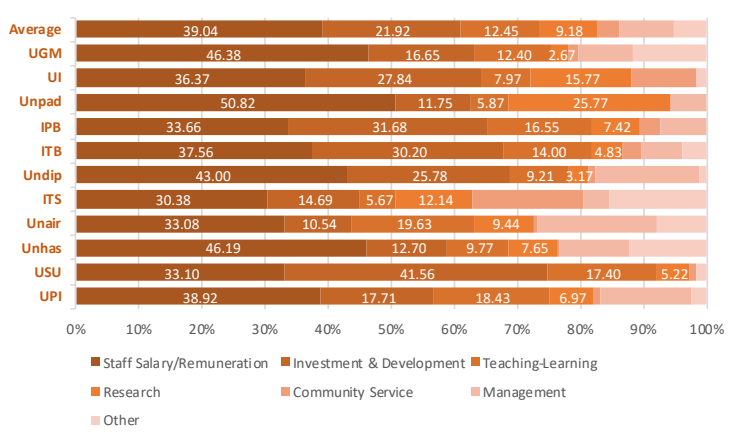

Figure 3. Proportion of PTN-BH expenditure year 2019

Note: UPI used data for the year 2018

PTN-BH has not yet been autonomous financially as expected. Several PTN-BHs have 
difficulty in being independent in managing funds received from the community and internal asset management as the funding from tuition is strictly regulated. The Minister of Research, Technology, and Higher Education Regulation number 39 the year 2017 concerning Single Tuition Fees in State HEIs provides a national standard for setting tuition fees. In this case, flexibility is only given in setting tuition fees for postgraduate programs and non-regular programs. Institutional autonomy of higher education institutions in Indonesia faces a paradox: pursuing management autonomy to improve service quality while still carrying out the mandate of affordability for the poor.

In terms of asset management, there was complexity in managing revenue from PTN-BH assets that stand on state land. For instance, UI has several assets that can be developed as sources of funding. However, the income received cannot be directly used because it is considered as income on state assets. The plan for land use must first be proposed to the Minister of Finance because it is related to the use of state assets. The permit issuance process also requires quite a long time. Moreover, funding sources obtained independently through asset management at PTN-BH (nonAPBN) are often considered infringement because they are part of the state's property.

As a state education institution, PTN-BH is naturally a non-profit organization. Nevertheless, it is still treated as a taxable subject. Such a policy often limits PTN-BH creativity in searching for additional funds outside APBN. Policies that are consistent with the provision of flexibility for more autonomous governance should be implemented. Taxation should not be targeted on PTN-BH as a legal entity, but on its business units which generates income. Thus, some government regulations need to be aligned with the reform agenda for higher education autonomy. Financial management must be more flexible and necessary to develop derivative regulations and technical guidelines in each PTN-BH.

\subsection{Governance}

Improving organizational governance is a vital part of PTN-BH's strategic objective. Good governance is measured by audit opinion of external auditors on the financial report, the proportion of students from low-income families, and the level of service user satisfaction. All academic management responsibilities are stated in the annual university report submitted to the Board of Trustees as the highest element in the PTN-BH institutional structure. To ensure that governance is carried out under the principles of good governance, external supervision, and inspection are carried out by a public accountant. Along with it, internal audits are conducted by PTN-BH internal auditor and the audit institution at the Board of Trustees level.

There is also a Minister of Research, Technology, and Higher Education Regulation number 50 the year 2018 concerning National Standard for Higher Education, which set the desired level of service. At the level of the university, several PTN-BH Chancellors have issued several regulations as implementation guidance in aspects, such as organization structure, title, and remuneration; financial operation; academic and teaching-learning; the standard cost of education provision; procurement of goods and services; intellectual property; partnerships; asset management; and endowment funds. The availability of technical regulations is crucial, in particular, to differentiate practice in PTN-BH that, in general, has been regulated in a higher order of regulation. In some cases, the inexistence of Chancellors-level regulation leads to audit findings because there is no solid ground for implementation. 
The organizational structure in PTN-BH is not yet streamlined and agile.

Around a quarter of the lecturers occupy structural positions. Even though this is allowed, it is reasonable to argue that a lean organizational structure promotes agility and efficiency. There are structural positions that have the potential to be inefficient, such as secretary of department/study program/section, which assists the head of department/study program/section. Only ITB and IPB do not have the position of such a secretary. PTN-BH also needs to consider lecturers' assignment in structural positions because it may reduce the time for teaching and research.

\subsection{Academic}

PTN-BH has extensive academic autonomy as regulated in Government Regulation number 4 in 2014 concerning the Implementation of Higher Education and Management of Higher Education. Academic autonomy has a vital role in supporting the realization of PTN-BH as $\mathrm{CoE}$. The autonomy includes the authority to open, change, and close study programs, curriculum, learning processes, assessment of learning outcomes, and graduation requirements.

In terms of the quality of education delivery, most of the study programs at PTN$\mathrm{BH}$ have been accredited A by the National Accreditation Board for Higher Education (BAN-PT). There were one to seven study program that accredited $\mathrm{C}$ in PTN-BH. These study programs were generally newly established. The supporting elements (mostly infrastructure) of education have not yet fully available.

2 ASEAN University Network-Quality Assurance (AUNQA); The Alliance on Business Education and Scholarship for Tomorrow (ABEST21); Akkreditierungsagentur für Studiengänge der Ingenieurwissenschaften, der
In addition to BAN-PT accreditation, PTN-BH strives for certification and accreditation from abroad to internationalize higher education services. AUN-QA is one of the international study program certification providers that is widely applied by PTN-BH. As for the accreditation, PTN-BH's choices include ABEST2 1, ASIIN, and ASIC ${ }^{2}$. For example, in 2019, Unair has 17 AUN certified study programs and 23 internationally accredited study programs ABEST21, ASIIN, and ASIC. The benefits of certification and accreditation are recognition from overseas communities and attracting international students. The degree of internationalization also accounted for the world university ranking.

To ensure the alignment of education service output with employment needs, almost all PTN-BH utilizes graduate tracer studies to determine future policies. For example, in Undip, tracer studies are used as input for system improvement and education management. ITS also utilizes tracer studies so that the curriculum and syllabus applied can adjust to market needs (industry demand).

To encourage the development of PTN$\mathrm{BH}$ as $\mathrm{CoE}$, universities' efforts in developing leading science fields have an essential role. Several PTN-BH has tried to encourage the development of competitiveness in specific science fields, through university policies in prioritizing a specific theme of research activities and increasing cooperation for the utilization of research products. For example, IPB, which seeks to focus on developing research in agriculture and animal husbandry, developed PUI in the fields of tropical horticulture, bio pharmacy, primate animals, and food security.

Informatik, der Naturwissenschaften und der Mathematik e. V.(ASIIN); The Accreditation Service for International Schools, Colleges, and Universities (ASIC) 
There is no mission differentiation policy. Ideally, PTN-BH as CoE focused on research and innovation, instead of striving in all Tridharma of Higher Education. In practice, PTN-BH must bear a double burden: to pursue the target of increasing the GER through expanding access to higher education services and accelerating the field of research in the framework of a world-class university. Also, in the name of the Tridharma function of higher education, lecturers must not only focus on the research function but also on teaching and community service. In this case, higher education institutions will need more resources and a longer time to get an edge.

\subsection{Cooperation}

ooperation becomes a vital aspect in the development of PTN-BH because it aims to increase the effectiveness, efficiency, productivity, creativity, innovation, quality, and relevance of the implementation of higher education. The partnership is built with various parties, namely universities, private companies, industry, government, and individuals, both in education, research, and community service.

Academic cooperation is a means to strengthen the quality of education in PTN-BH. It carried out in the form of (1) cooperation in the development of science; (2) research; (3) publishing scientific papers and books; (4) exchange of speakers and experts; (5) education and training programs for students, lecturers, and education staff; (6) joint seminars; and (7) sharing research and laboratory equipment. Academic cooperation in PTN-BH is predominantly among Indonesian HEIs. There are apparent challenges in establishing international cooperation, such as outdated research facilities, uncompetitive international researchers and professors remuneration, and difficulties in getting residence visas for researchers and professors.
In general, non-academic cooperations are developed to strengthen institutional governance and achieve PTN-BH performance targets. Forms of non-academic cooperation include cooperation in community service, development and improvement of organizational capacity, student affairs, personnel, facilities and infrastructure, and governance.

Most PTN-BH have a business unit. The unit is tasked to carry out planning, approaching, interweaving, and cooperation agreements centrally with various parties both domestically and abroad. Thus, if there are other work units or individuals who wish to enter into a cooperation contract, the party must report and submit all cooperative matters to the cooperation unit. On the other hand, Gadjah Mada University provides flexibility for all work units to establish a partnership with external entities under the guidelines for implementing cooperation.

Cooperation with the business world and industry is expected to spur the commercialization of innovative research results. However, the cooperation is still not optimal due to various issues, such as (1) research results that are not in line with industry needs; (2) The level of technological readiness of $\mathrm{PTN}-\mathrm{BH}$ research results is still low; (3) the difficulty of an agreement that is mutually beneficial to both parties; and (4) the absence of mapping the results of research and innovation products owned by PTN-BH.

\subsection{Research and Innovation}

Research in PTN-BH is regarded as highquality research and accordingly, is directed to produce more tangible outputs that give an economic benefit. In 2019 there were 431.8 billion rupiahs dedicated for research in eleven PTN-BH, while as much as 858.4 billion rupiahs are distributed (and competed) to 125 state- 
owned HEIs. Each of PTN-BH received a fixed amount of research grant based on research performed in the previous year.

Research at PTN-BH often only ends in the form of publication. Lectures were only fulfilling obligations stipulated in the Minister of Research, Technology, and Higher Education number 20 the year 2017. Beyond journal publication, most of the PTN-BH research results are still at the low technology readiness level (level 1 to 5 out of 9 levels). On the other hand, the business and industries in favor of technology-ready or even market-ready products to maximize profits. Involvement (investment) in the early stages of product development is seen as a high-cost and high-risk decision. Thus, the business world and industry are relatively reluctant to cooperate in developing these innovative products. The lack of cooperation and asymmetric information between PTN-BH and industry makes constraints in research product commercialization.

The availability of research facilities and infrastructure is an essential factor in innovation. PTN-BH requires the latest research equipment to support the improvement of the quality of innovative research results, but this requires considerable capital investment and maintenance costs. Even though most of PTN-BH have received infrastructure development through Government external loans in the past decade, low quality and outdated pieces of equipment still exist. Sometimes they were not suitable for use, which will affect the quality and validity of the research produced.

The creation of innovations at PTN-BH has been supported by the existence of supporting components, such as a dedicated organizational unit for innovation, the center of science and technology excellence, business incubators, and science and technopark (STP).
For example, in IPB, there is a Directorate of Research and Innovation, which oversees 24 study centers in the rector's organizational structure. At the lower organizational structure, there are IPB Science and Technology Park, IPB business incubator (incuBie), and four PUIs.

Our findings found that ITB, IPB, UGM, and ITS have a more established innovation institution. In those three PTN-BH, the are innovation-related units at the top management level, established science and technology park, as well as PUI and incubator. The condition is favorable for the innovation ecosystem, together with industry involvement in research and development activities. UI, UPI, USU, Unair, and Unhas do not have a science and technology park (STP), so their innovation processes were undertaken through technology business incubator.

The number of patents owned by PTN$\mathrm{BH}$ institutions is still limited. The most significant number of patents is owned by Undip up to 187 patents, while UPI and Unpad are still minimal (DGIP, 2019). Some patents are registered in the name of personal, not institutional. The individually-registered patent indicates that the institution's role in facilitating patent management is not optimal, or the research is externally funded.

PTN-BH is having difficulties disseminating research results to enter the mass production stage in the industry. There are not many supportive regulations in favor of PTNBH. Often, PTN-BH is underhanded when it comes to an agreement with the industry. For example, if a company cooperates in the utilization of R\&D and technology owned by ITB, the compensation that can be received by ITB is only in the form of royalty sharing on patents. The industry is not opened to capital investment (shares) from ITB.

The creation of an innovation ecosystem requires policy support from university leaders. 
For instance, the innovation ecosystem at ITS is supported by the Grand Design Entrepreneurial University in 2035 and the development of the ITS STP. At the same time, several internal regulations were issued to support the growth of the innovation climate, including Chancellor Regulations related to KST Managers, Chancellor Regulations on the Technology Transfer Office Team Chancellor Regulations on Intellectual Property.

\section{Development Toward Centre of Excellence}

\subsection{International Practices}

The development of higher education as a $\mathrm{CoE}$ has been widely carried out in various countries. Establishing a $\mathrm{CoE}$ at an HEI shifts the focal point of activities from educational services (teaching universities) to research and development (research universities). For example, in early 2000, Nanyang Technological University (NTU) in Singapore initially focused on teaching and a few research groups. Now, NTU has developed into a research university. CoE development in NTU is driven by research experts (non-lecturer researchers) who conduct multidisciplinary research, in collaboration with various parties (Lim and Boey, 2014). South Korea is running a massive national program, Brain Korea 21 (BK21), with a substantial research budget. There were approximately 11 HEIs with specialized competencies developed into CoE through research fund incentives from the South Korean Government. Through BK21, South Korea is developing $\mathrm{CoE}$ in the latest science, technology, socio-cultural and economic fields (Kang, 2015).

In Indonesia, the 11 PTN-BHs with the capacity and autonomy are highly likely to be developed as CoE. These PTN-BH are generally considered to be more advanced in terms of infrastructure and human resources for research, which is indicated by the number of research outputs compared to Non-PTN-BH. However, unlike other countries, all HEIs in Indonesia, including PTN-BH, still carry out the mandate to carry out the Tridharma of Higher Education. The mission of differentiation policy has not yet carried out to enable a favorable innovation environment.

\subsection{Defining CoE in Indonesia Context}

Currently, there is no single definition and criteria of $\mathrm{CoE}$ at the national level. There are various interpretations at the PTN-BH level, which can be clustered into three groups. The first group defines $\mathrm{CoE}$ if an HEI excels in the three Tridharma of Higher Education, i.e., education, research, and community service. Therefore, there is no particular field of science or research that is promoted or favored because all science fields are equally important. The second group sees $\mathrm{CoE}$ as the excellence in a particular research field, which is closely related to the potential of resources in the area where the HEI is located. The specialty of the CoE can be different from PUI. Finally, the third group defines $\mathrm{CoE}$ is the PUI, which is nurtured and appointed by the MoRTHE.

PUI can be a solid starting point for $\mathrm{CoE}$ development in PTN-BH. PUI has received a three-years of coaching interventions from MoRTHE towards credible and financiallyindependent research institutions. To be appointed as PUI there are strict prerequisites, such as (1) ability to absorb information and technology from the outside, (2) ability to develop research activities based on market demand and international standards, (3) ability to disseminate international quality research results, and (4) develop and preserve the potential of local resources in a sustainable manner. These are considered to be quite sound modalities towards CoE. 
Defining $\mathrm{CoE}$ as a $\mathrm{CoE}$ in terms of research and development can be translated as focusing on services (mission of differentiation) as a research university. Although PTN-BH is still burdened with assignments to increase enrolment rates, a sufficient portion of budgeting must be allocated to build a reputation as a research university. The $\mathrm{CoE}$ will eventually become a cross-campus and cross-country cooperation hub in specific fields. As discussed in the earlier section, a $\mathrm{CoE}$ at PTN-BH can be financially independent than those at PT-BLU or PT-Satuan Kerja.

\subsection{Gap Analysis towards $\mathrm{CoE}$}

The CoE needs to be supported by conducive environmental conditions at the HEI level. Such an environment can be measured through $\mathrm{CoE}$ forming components: funding, cooperation, governance/management, academic, and research, and innovation. The following table analyzes gaps between existing conditions in PTN-BH compared to the expected ideal condition.

Table 3. Gap analysis for $11 \mathrm{PTN}-\mathrm{BH}$

Ideal Condition for $\mathrm{CoE}$

Existing Condition

(field findings)
Gap Analysis

(Causes)

\section{Financial/Funding}

\section{Revenue:}

- HEI can generate income from non-APBN

- Tuition fee as a source of funding is below $50 \%$

- HEI can explore nongovernment funding sources related to education development (ex: lab equipment rental, research, and nonresearch collaboration)

\section{Quality of budget utilization:}

- Components that receive priority budgeting (ops-salary benefits/maintenance and nonops-research/procurement of laboratories and tools/quality development of human resources)

- The proportion of funding for the research component $(>50 \%$ of total non-ops)

\section{Revenue:}

- Around $33 \%$ of PTN-BH revenue comes from APBN

- Tuition fee as a source of funding is below $50 \%$

- There are no PTN-BH innovations in exploring sources of nongovernment funding related to education development

\section{Quality of budget} utilization:

- Components that receive priority budgeting are more dominated operations (salary/benefits/ maintenance)

- The proportion of funding for the research component $(<50 \%$ of

\section{A large gap which} requires Government support. Almost all PTN$\mathrm{BH}$ have not been able to explore non-APBN funding sources optimally. Factors causing, including:

- Financial autonomy has not been fully implemented. Specific regulations limit the authority of PTN-BH (asset management, funding from tuition fees, and the imposition of tax on PTN-BH);

- The business unit has not been able to provide significant additional funding;

- Commercialization R\&D results are not optimal.

- The utilization of the budget is still dominant for operational costs 


\begin{tabular}{lll}
\hline Ideal Condition for CoE & $\begin{array}{c}\text { Existing Condition } \\
\text { (field findings) }\end{array}$ & \multicolumn{1}{c}{$\begin{array}{c}\text { Gap Analysis } \\
\text { (Causes) }\end{array}$} \\
\hline $\begin{array}{lll}\text { total non-operational } \\
\text { costs) }\end{array}$ & $\begin{array}{l}\text { rather than for research } \\
\text { and } \\
\text { components development }\end{array}$ \\
\hline
\end{tabular}

\section{Cooperation}

- How HEI attracts collaboration (actively participates in various consortium activities, seminars, joint research, submits proposals)

- Research and innovation products that have been successfully developed through the collaboration of HEI (more collaboration is preferred)

- Lecturer / researcher mobility with industry or state-owned enterprise (broader scope is preferred)
- PTN-BH not actively seeking attract commercial cooperation (passive).

- Research and innovation products that have been successfully developed through PTN-BH collaboration are still few or non-existent

- The mobility of lecturers/ researchers with the industry and/or BUMN is still small/non-existent

\section{A large gap which requires Government support:}

- Strategic research cooperation and innovation development of PT-BH is not running optimally even though almost all PTN-BH already have a cooperation unit;

- Cooperation with industry is generally constrained due to asymmetric information.

- Cooperation with international HEI still limited.

\section{Governance}

- There are regulations issued by each HEI (Chancellor Decree / similar) to support the HEI's governance system, especially those that support the development of $\mathrm{CoE}$ components.

- External financial audit results unqualified for the past three years

- A sound reporting system transparent and accountable computer-based

- PTN-BH HR development efforts (through training and education) and reward for lecturers/educators/researchers
- There are no regulations issued by each chancellor to support the governance system in PTN-BH comprehensively

- Most PTN-BH has an unqualified financial report. But not in the three consecutive years.

- A reporting system that is still manual (not yet computer-based)

- Almost all PTN-BH have already carried out tracer studies and

\section{A small gap which can be} managed by PTN-BH. The gap exists especially for the governance of non-academic affairs:

- Authority for the governance of nonacademic affairs is still limited, including in terms of financial and asset management.

- Several regulations hinder the principle of autonomy. Even though in some case can be solved by enacting chancellor decree/regulation 
Ideal Condition for $\mathrm{CoE}$

who perform well (for example outstanding lecturers, lecturers who produce the most publications)

- PTN-BH considers and utilizes tracer studies of graduates and users/industry for future policies

\section{Existing Condition}

(field findings)

utilized them for future policies

\section{Gap Analysis}

(Causes)
- Only a few universities have developed computerbased reporting systems (UI, ITS, Unpad).

\section{Academic}

- The relevance of leading fields developed based on vision and mission in the HEI's Strategic Plan

- The proportion of study programs accredited A compared to the total study programs

- The proportion of internationally accredited study programs compared to total study programs

- The number of international students compared to the total

- The proportion of doctoral lecturers

- The proportion of postgraduate students compared with graduates

- Internationalization programs (example: double degree, worldclass professor)
- The development of superior fields is quite in line with the PTNBH Strategic Plan

- Almost all of the study programs at PTN-BH have been accredited $\mathrm{A}$.

- The number of international students in all PTN-BH is minimal with the ratio of international students: local is around 4:96

- The number of doctoral holders in almost all PTN-BH is still lacking. Generally, it is still dominated by masters holder lecturers

- The proportion of undergraduate and graduate students varies and is relatively relative when compared to foreign universities

- Internationalization program interventions

\section{A small gap which can be} managed by PTN-BH:

- Most PTN-BH already have a vision and mission and intervention in the development of superior fields, although it still needs to be sharpened by the dynamics of industry needs;

- An effort is still needed to improve the lecturer qualifications to a doctoral degree;

- Almost all PTN-BH are still oriented towards teaching, not to research universities. Therefore, undergraduate students are still dominant. 


\begin{tabular}{|c|c|c|}
\hline Ideal Condition for $\mathrm{CoE}$ & $\begin{array}{l}\text { Existing Condition } \\
\text { (field findings) }\end{array}$ & $\begin{array}{l}\text { Gap Analysis } \\
\text { (Causes) }\end{array}$ \\
\hline & $\begin{array}{l}\text { are already running at } \\
\text { PTN-BH but still need } \\
\text { to be optimized. }\end{array}$ & \\
\hline \multicolumn{3}{|c|}{ Research and Innovation } \\
\hline $\begin{array}{l}\text { - The proportion of start-ups } \\
\text { produced by HEI from the } \\
\text { number of tenant proposals } \\
\text { (more is preferred) } \\
\text { - The proportion of start-up that } \\
\text { develops into an established } \\
\text { start-up company/business } \\
\text { spinoff (more is preferred) } \\
\text { - The number of patents produced } \\
\text { compared to the number of } \\
\text { royalties obtained by HEI (the } \\
\text { more number of patents should } \\
\text { increase the number of royalties } \\
\text { obtained by HEI proportionally }\end{array}$ & $\begin{array}{l}\text { - Most PTN-BH have } \\
\text { not been able to } \\
\text { produce large amounts } \\
\text { of start-ups. } \\
\text { - The start-up coaching } \\
\text { program has been } \\
\text { running for more than } \\
\text { four years, but not } \\
\text { many can progress into } \\
\text { an established start-up } \\
\text { company. } \\
\text { Most of the university } \\
\text { research results stop at } \\
\text { the output } \\
\text { laboratory-scale } \\
\text { prototypes, IPRs, and } \\
\text { international } \\
\text { publications. Patent } \\
\text { innovation products } \\
\text { that produce royalties } \\
\text { are still limited. }\end{array}$ & $\begin{array}{l}\text { A large gap which } \\
\text { requires Government } \\
\text { assistance. The innovation } \\
\text { ecosystem in most PTN-BH } \\
\text { is not optimal: } \\
\text { - Only a small number of } \\
\text { PTN-BH can produce } \\
\text { start-ups, and the } \\
\text { number is still limited, } \\
\text { such as ITB, UGM, ITS, } \\
\text { IPB; } \\
\text { - The results of research } \\
\text { at PTN-BH have not } \\
\text { been fully able to be } \\
\text { utilized/commercialized. } \\
\text { Income generation from } \\
\text { this component is still } \\
\text { limited in most PTN- } \\
\text { BH. }\end{array}$ \\
\hline
\end{tabular}

\section{Conclusion and Policy Recommendation}

Having discussed the current modalities of PTN-BH, the development towards $\mathrm{CoE}$ is possible, but a substantial intervention is needed. Special attention is needed to close gaps in funding/financial, cooperation, and research and technology components.

Innovative in sourcing other revenues outside APBN and community contributions are still limited. Revenues from the business unit have not been able to provide significant additional funding. Accordingly, strategic funding and financial management policy should be set to promote a more financial autonomy practice. Based on the findings above, future policy recommendations include:

- Review the technical regulations of financial management that hinder or contradict the principle of PTN-BH autonomy. For example, improving regulations related to the management of state assets to be optimized by PTN-BH as a source of income. It is also necessary to improve tax regulations for PTN-BH which are naturally non-profit (specific arrangements relating to what activities are subject to income tax or which PTN-BH elements are subject to income tax); 
- Promote mission differentiation for each state university group, i.e., PTN-BH is given mission to strengthen research capacity for the development of science and create innovative products of high economic value (research universities) rather than increasing education access. Accordingly, lecturers are given independence in deciding the worktime allocation between research, teaching, and community services;

- Optimizing the utilization of education endowment funds based on PTN-BH's mission;

- Promote a capped government matching fund scheme for productive activities in PTN-BH; and

- Gradually reduce the amount of funding allocation from the Government in line with the financial independence of PTN-BH.

The performance of PTN-BH cooperation is highly dependent on internal regulations and the presence of units that specifically work on the cooperation network. Some strategies can be set to improve cooperation in PTN-BH:

- Strengthening the internal organizational structure of PTN-BH that handles cooperation;

- The establishment and development of a PTN-BH innovative research collaboration consortium with industry and world-class universities; and

- Government facilitation in formulating internal regulations related to cooperation, especially for commercially oriented cooperation.

Most PTN-BH do not yet have a research and innovation road map. Also, the commercialization of research and innovation results at PTN-BH is still not optimal due to the lack of researchers' synergy with the business world and industry. Innovation ecosystem at
PTN-BH still needs to be improved, which can be achieved through strategies such as:

- Encouraging the establishment of a technology transfer office at PTN-BH;

- Develop PUI to be more independent and productive in producing research products and innovative products;

- Facilitating PTN-BH to develop or strengthen the intellectual property management system;

- Forming a research consortium to foster research collaborations with industry and world-class foreign companies to produce research products that have added value, marketable, and generate economic benefits for PTN-BH and encourage the development of scientific fields and innovative research climate; and

- Together with the Ministry of Education and Culture and the Ministry of Research and Technology/BRIN created a database platform for cooperation in developing innovative products with industry.

Finally, a university-level regulation (chancellor regulation or decree) that governs technical guidance should be put in place before PTN-BH driving towards CoE.

\section{References}

Fachriansyah, K. (2018). Unravelling the Relationship between Education Structure and Growth Rate Disparities among the Selected Developing Countries. The Indonesian Journal of Development Planning, 2(3), p.259-273. https://doi.org/10.36574/jpp.v2i3.50

Hellstrom, T. (2018). Centres of Excellence and Capacity Building: from Strategy to Impact. Science and Public Policy, Vol. 45, Issue 4, August 2018, p. 543-552. https://doi.org/10.1093/scipol/scx082. 
Hrnčiar, M. and Madzik, P. (2013). Improving the Quality of Higher Education in Central Europe: Approach Based on GAP Analysis. Higher Education Studies, Vol. 3, No. 4, p. 75-88. http://dx.doi.org/10.5539/hes.v3n4p75.

Kang, J. (2015). Initiatives for Change in Korean Higher Education: Quest for Excellence of World-Class Universities. International Education Studies; Vol. 8, p. 169-180. doi: 10.5539/ies.v8n7p169.

Law No. 12/2012 concerning Higher Education. Indonesia.

Lim, C. and Boey, F. (2014). Strategies for academic and research excellence for a young university: perspectives from singapore. Ethics in Science and Environmental Politics, Vol. 13, p.113-123. doi: 10.3354/esepoo139.

Government Regulation No.4/2014 concerning Implementation of Higher Education and Management of Higher Education. Indonesia.

Government Regulation No. 26/2015 concerning the Form and Mechanism of PTN-BH Funding. Indonesia.

Minister of Education and Culture Regulation No. 14/2004 concerning Higher Education Cooperation. Indonesia.

Minister of Education and Culture Regulation No. 88/2014 concerning the Change of PTN into PTN-BH. Indonesia.

Minister of Research, Technology and Higher Education Regulation No. 22/2015 concerning Single Tuition Fees and Single Tuition Fees at State Universities in the Ministry of Research and Technology. Indonesia.

Minister of Research, Technology and Higher Education Regulation No.40/2016 concerning Guidelines for the Preparation of PTN-BH Performance Reports. Indonesia.
Salmi, J. (2009). The Challenge of Establishing World-Class Universities. Washington, DC: the World Bank.

UNESCO Institute for Statistics. (2014). Higher Education in Asia: Expanding Out, Expanding UP - The rise of graduate education and university research. Montreal: UNESCO Institute for Statistics. 